\title{
Management of Discharged Emergency Department Patients with a Primary Diagnosis of Hypertension: A Multicentre Study
}

\author{
Dennis D. Cho, MD*; Peter C. Austin, $\mathrm{PhD}^{\dagger}$; Clare L. Atzema, MD, $\mathrm{MSc}^{{ }^{\dagger \ddagger}}$ \\ ABSTRACT \\ RÉSUMÉ
}

Introduction: Many patients are seen in the emergency department (ED) for hypertension, and the numbers will likely increase in the future. Given limited evidence to guide the management of such patients, the practice of one's peers provides a de facto standard.

Methods: A survey was distributed to emergency physicians during academic rounds at three community and four tertiary EDs. The primary outcome measure was the proportion of participants who had a blood pressure (BP) threshold at which they would offer a new antihypertensive prescription to patients they were sending home from the ED. Secondary outcomes included patient- and providerlevel factors associated with initiating an antihypertensive based on clinical vignettes of a 69-year-old man with two levels of hypertension (160/100 vs 200/110 $\mathrm{mm} \mathrm{Hg}$ ), as well as the recommended number of days after which to follow up with a primary care provider following ED discharge.

Results: All 81 surveys were completed (100\%). Half (51.9\%; $95 \% \mathrm{Cl} 40.5-63.1)$ of participants indicated that they had a systolic BP threshold for initiating an antihypertensive, and $55.6 \%(95 \% \mathrm{Cl} 44.1-66.6)$ had a diastolic threshold: mean systolic threshold was $199 \mathrm{~mm} \mathrm{Hg}$ (SD 19) while diastolic was $111 \mathrm{~mm} \mathrm{Hg}$ (SD 8). A higher BP (OR 12.9; $95 \% \mathrm{Cl}$ 7.5-22.2) and more patient comorbidities (OR 3.0; $95 \% \mathrm{Cl} 2.1-4.3)$ were associated with offering an antihypertensive prescription, while physician years of practice, certification type, and hospital type were not. Participants recommended follow-up care within a median 7.0 and 3.0 days for the patient with lower and higher BP levels, respectively.

Conclusions: Half of surveyed emergency physicians report having a BP threshold to start an antihypertensive; BP levels and number of patient comorbidities were associated with a modification of the decision, while physician characteristics were not. Most physicians recommended follow-up care within seven days of ED discharge.
Introduction: Beaucoup de patients sont examinés au service des urgences (SU) pour de I'hypertension, et leur nombre augmentera probablement au cours des prochaines années. Compte tenu du peu de données probantes sur le traitement et le suivi de ces patients, la pratique des pairs constitue une sorte de norme de fait.

Méthode: Un questionnaire d'enquête a été remis à des médecins d'urgence durant des tournées de formation théorique dans trois SU d'hôpitaux communautaires et dans quatre SU d'hôpitaux de soins tertiaires. Le principal critère d'évaluation était la proportion de participants qui appliquaient un seuil de pression artérielle (PA) à partir duquel ils étaient prêts à offrir une nouvelle prescription d'antihypertenseurs aux patients avant de les retourner à domicile. Les critères d'évaluation secondaires comprenaient des facteurs liés aux patients ou aux fournisseurs de soins, et associés à I'instauration d'un traitement antihypertenseur dans le contexte de scénarios cliniques décrivant un homme de 69 ans, atteint d'hypertension (deux degrés: 160/100 ou 200/110 mm $\mathrm{Hg}$ ), ainsi que le nombre de jours recommandé pour assurer le suivi par un fournisseur de soins primaires après le congé du SU.

Résultats: Tous les sondés, soit 81 , ont répondu au questionnaire (100\%). La moitié des participants (51,9\%; IC à $95 \%$ : 40,5$63,1)$ ont indiqué appliquer un seuil de pression systolique (PS) pour entreprendre un traitement antihypertenseur, et 55,6 \% (IC à $95 \%$ : 44,1-66,6) ont indiqué appliquer un seuil de pression diastolique (PD); le seuil moyen de PS était de $199 \mathrm{~mm} \mathrm{Hg}$ (écarttype: 19) et le seuil moyen de PD, de $111 \mathrm{~mm}$ Hg (écart-type: 8). Des valeurs élevées de PA (risque relatif approché [RRA]: 12,9; IC à $95 \%: 7,5-22,2$ ) et la présence de maladies concomitantes (RRA: 3,0; IC à $95 \%: 2,1-4,3$ ) ont été associées à l'offre d'un traitement antihypertenseur, tandis que le nombre d'années de pratique des médecins, le type de certificat et le type d'hôpital ne l'étaient pas. Les participants ont recommandé un délai médian de 7,0 jours et de 3,0 jours, respectivement, pour le suivi des patients ayant une PA plus basse et une PA plus haute.

From the *Division of Emergency Medicine, Department of Medicine, University of Toronto, Toronto, ON; tInstitute for Clinical Evaluative Sciences, Toronto, ON; and ¥Sunnybrook Health Sciences Centre, Toronto, ON

Correspondence to: Clare Atzema MD, MSc, Institute of Clinical Evaluative Sciences, 2075 Bayview Avenue, Rm G157, Toronto, ON M4N 3M5; Email: clare.atzema@ices.on.ca 
Conclusions: La moitié des médecins d'urgence qui ont participé à l'enquête ont indiqué appliquer un seuil de PA pour l'amorce d'un traitement antihypertenseur; les valeurs de PA ainsi que le nombre de maladies concomitantes ont été associées à une modification de la décision, tandis que les caractéristiques des médecins, elles, ne l'étaient pas.
La plupart des médecins ont recommandé un suivi dans les sept jours après le congé du SU.

Keywords: Hypertension, Emergency Department, Follow-up Care, Continuity of Care, Evidence-Based Medicine

\section{INTRODUCTION}

Hypertension is the leading risk factor for death worldwide and leads to significant morbidity and mortality secondary to conditions such as myocardial infarction, stroke, and renal failure. ${ }^{1}$ In Canada, almost a quarter of the adult population has hypertension; ${ }^{2}$ worldwide, it affects one billion individuals. ${ }^{3}$ Given the increasing prevalence of hypertension, ${ }^{4}$ it follows that visits to the emergency department (ED) for hypertension and its sequellae can also be expected to increase. ${ }^{5,6}$ The aging population ${ }^{6}$ and increased use of home blood pressure (BP) measuring devices ${ }^{7}$ will likely further impact ED visits for hypertension in the coming decades.

For patients with hypertension but without a hypertensive emergency, there is an absence of evidence to guide ED management. ${ }^{8} \mathrm{We}$ suspect that this results in wide practice variation amongst emergency physicians. Whether or not emergency physicians routinely offer new antihypertensive prescriptions (or increase the dose of pre-existing prescriptions) is unknown, as is the timeframe within which they advise patients to obtain follow-up care. Most of the existing emergency medicine literature on this topic has extrapolated from primary care guidelines to the ED setting. ${ }^{8,9}$ The 2006 American College of Emergency Physicians (ACEP) policy statement indicates that patients with asymptomatic hypertension require "prompt... follow up with their primary physician;" however, a specific timeframe was absent. ${ }^{10}$

In the absence of evidence, the practice of one's peers forms a de facto standard. The purpose of our study was two-fold: (1) to establish whether there is a threshold BP at which emergency physicians will initiate or modify antihypertensive medications; and (2) to determine the follow-up interval recommended by emergency physicians for patients discharged from the ED with asymptomatic elevated blood pressure.

\section{METHODS}

\section{Study design}

We performed a cross-sectional survey of emergency physicians attending rounds at seven sites in the Greater Toronto Area (GTA), or Emergency Medicine Grand Rounds for the University of Toronto, in September and October 2013. Research Ethics Board approval was obtained from the Sunnybrook Health Sciences Centre.

\section{Setting and participants}

The GTA has a catchment area of approximately six million people ${ }^{11}$ served by five tertiary and 13 community EDs (excluding specialty EDs). Nearly all sites have at least monthly ED rounds; a convenience sample of seven sites was selected (Table 1) with the aim of having a roughly equal number of tertiary and community EDs. Participants had to be certified emergency physicians, either through the Royal College of Physicians and Surgeons of Canada (RCPSC) or the College of Family Physicians of Canada (CFPC). In-person recruitment at ED rounds was specifically utilized to avoid the poor response rates typical with electronic surveys. ${ }^{12,13}$

\section{Methods of measurement}

The principal investigator (DDC) attended each rounds, provided a standardized verbal summary of the rationale of the study to all attendees, and then distributed the surveys to individuals who self-identified as certified emergency physicians. It was emphasized that the study aimed to determine usual practice rather than perceived "ideal practice." No further guidance about survey content was provided.

The one-page survey included physician demographic information, eight general questions regarding BP thresholds, and a series of specific questions surrounding 


\begin{tabular}{|c|c|c|}
\hline \multicolumn{3}{|c|}{ Study Sites in the Greater Toronto Area (Ontario) } \\
\hline Sunnybrook Health Sciences Centre & & Toronto \\
\hline Toronto General Hospital & & Toronto \\
\hline St Michael's Hospital & & Toronto \\
\hline Toronto Western Hospital & & Toronto \\
\hline Markham-Stouffville Hospital & & Markham \\
\hline North York General Hospital & & North York \\
\hline Credit Valley Hospital & & Mississauga \\
\hline Characteristic & $\mathrm{n}=81(\%)$ & Reported a Prescription Threshold (\%) \\
\hline Mean \# years in practice (SD) & $11.5(10)$ & \\
\hline Median \# years in practice (IOR) & $9.0(3.0-16.5)$ & \\
\hline \multicolumn{3}{|l|}{ Certification } \\
\hline CCFP (\%) & $6(7)$ & * \\
\hline CCFP-EM (\%) & $39(48)$ & $20(51.3)$ \\
\hline FRCPC-EM (\%) & $33(41)$ & $19(57.6)$ \\
\hline Other (MD only, \%) & $2(3)$ & * \\
\hline Not specified/Missing (\%) & $1(1)$ & * \\
\hline \multicolumn{3}{|l|}{ Working environment } \\
\hline Academic (tertiary) (\%) & $40(49)$ & $20(50.0)$ \\
\hline Community (\%) & $32(40)$ & $14(43.8)$ \\
\hline Both tertiary and community (\%) & $9(11)$ & $8(88.9)$ \\
\hline
\end{tabular}

six related clinical vignettes (Figure 1). Both general questions and clinical vignettes were employed to serve as different approaches to answer the research questions, in the event that participants answered differently when presented with a specific clinical case. Each patient presented in the vignettes had a final ED diagnosis of hypertension and was deemed fit for discharge by the managing emergency physician after a work-up revealed no end-organ damage, and was assumed to have a primary care physician with whom they could follow up. ${ }^{14}$ Blood pressures of $160 / 100 \mathrm{~mm} \mathrm{Hg}$ (the threshold for stage 2 hypertension) and 200/110 mm $\mathrm{Hg}$ were chosen for the vignettes to provide extremes that would help determine whether the degree of hypertension modified decision-making. ${ }^{3,7}$ The survey was pilot-tested on 10 emergency physicians and adjusted as necessary.

\section{Outcome measures}

The primary outcome was the proportion of physicians who reported having a threshold systolic and/or diastolic $\mathrm{BP}$ at which they would prescribe a new antihypertensive or increase the dose of a pre-existing antihypertensive.
For those who reported a threshold, specific BP values were elicited. Secondary outcome measures included: (1) the association of patient-level factors (BP values and number of relevant comorbidities) and provider-level factors (years in practice, practice certification, and hospital type) on antihypertensive prescription provision; and (2) the number of days emergency physicians recommended for follow-up with a primary care physician.

\section{Primary data analysis}

Responses were entered into an Excel file (Microsoft Corp., Redmond, WA) with double data entry on $100 \%$ of the responses. Range and logic checks were performed and descriptive statistics were generated. To examine which variables were associated with offering or increasing an antihypertensive prescription, logistic regression modeling was utilized using generalized estimating equations to account for clustering on physician (since the same physician responds to all questions in a single survey). Patient-level factors and emergency physician factors were regressed on new antihypertensive prescription provision in the first model and on an 
Follow-Up Recommendations for Severe Hypertension in the ED Cho DD \& Atzema CL
Study ID:

Protocol Date: $\overline{\text { March } 11}, \overline{2013}$

REB Project ID: 121-2013

\section{Towards a clinical guideline for the recommended follow-up interval for patients presenting to the ED with asymptomatic hypertension By filling out this survey, your consent is implied}

\section{Demographic Information:}

1. Name:

2. Years in practice (number):

3. Certification (circle): CCFP CCFP-EM FRCPC Other:

4. Type of hospital where you work (circle all that apply):

$$
\text { Academic/Tertiary Community Retired Other: }
$$

\section{Current Practice:}

5. In a patient with a primary ED diagnosis of "hypertension":

- who is asymptomatic and without any signs of end-organ failure,

- and who has a family doctor for follow-up care

- and you are discharging from the ED...

a) $\ldots$ is there a specific SBP at which point you would prescribe an anti-hypertensive or increase a pre-existing one? Circle: Yes / No

If Yes, please specify: systolic _ $\mathrm{mm} \mathrm{Hg}$

b) $\ldots$ is there a specific DBP at which point you would prescribe an anti-hypertensive or increase a pre-existing one? Circle: Yes / No

If Yes, please specify: diastolic $\mathrm{mm} \mathrm{Hg}$

6. Three patient scenarios follow. As above, all have a primary ED diagnosis of "hypertension" and are asymptomatic, have a family doctor for follow-up care, and are ready to be discharged

\begin{tabular}{|l||c|c||c|c||c|c||}
\cline { 2 - 6 } \multicolumn{1}{l||}{} & \multicolumn{2}{c||}{$\begin{array}{c}\text { a. 69 M with hx of } \\
\text { dyslipidemia }\end{array}$} & \multicolumn{2}{c||}{$\begin{array}{c}\text { b. 69 M with hx of } \\
\text { HTN \& diabetes }\end{array}$} & \multicolumn{2}{c||}{ c. 69 M with hx of diabetes \& CHF } \\
\hline ED BP (mm Hg): & $160 / 100$ & $200 / 110$ & $160 / 100$ & $200 / 110$ & $160 / 100$ & $200 / 110$ \\
\hline $\begin{array}{l}\text { If not on an anti- } \\
\text { HTN med, would } \\
\text { you start one? Y/N }\end{array}$ & & & & & & \\
\hline $\begin{array}{l}\text { If on an anti-HTN } \\
\text { med, would you } \\
\text { increase? Y/N }\end{array}$ & & & & & & \\
\hline $\begin{array}{l}\text { You would tell the } \\
\text { patient to F/U with } \\
\text { family dr within } \\
\text { what \# of days? } \\
\text { (use "zero" if no } \\
\text { F/U required) }\end{array}$ & & & & & & \\
\hline
\end{tabular}

Figure 1. Survey instrument.

increased dose in the second. To evaluate whether physicians actually practiced as they indicated in the survey, we performed a post-hoc analysis on an existing dataset (collected via chart review) ${ }^{15}$ of discharged patients with a primary diagnosis of hypertension from two study sites in fiscal year 2010. Data were analyzed using SAS software (Version 9.2, SAS Institute Inc., Cary, NC).

\section{RESULTS}

Surveys were offered to 81 eligible emergency physicians from seven hospital sites. The response rate was $100 \%$, missing data was $<1 \%$, and double-data entry had extremely high agreement $(\kappa=0.94-1.00$ for all variables). Characteristics of the study participants are shown in Table 1.

\section{Blood pressure thresholds}

In all, $51.9 \%$ (95\% CI, 40.5-63.1) of participants reported having a specific systolic BP threshold that would trigger them to write a prescription for a new antihypertensive and $48.1 \%$ (95\% CI, 36.9-59.5) reported having a systolic BP threshold for increasing 
the dose of a pre-existing antihypertensive. Of those who would offer a new antihypertensive prescription or increase a pre-existing prescription, the median threshold values were both $200 \mathrm{~mm} \mathrm{Hg}$ (IQR 180-210 and 180-200, respectively).

In all, 55.6\% (95\% CI, 44.1-66.6) of participants reported having a diastolic threshold that would trigger a new antihypertensive prescription and $49.5 \%$ (95\% CI, 38.1-60.7) reported a threshold for increasing the dose of a pre-existing prescription. The median diastolic threshold values reported by participants who would offer a new antihypertensive prescription or increase a pre-existing prescription were both $110 \mathrm{~mm} \mathrm{Hg}$ (IQR 110-120 and 100-120, respectively).

In response to the clinical vignettes, $5 \%$ of participants reported that they would offer a new prescription for a 69-year-old male with dyslipidemia and a BP of 160/100 mm Hg (Table 2). Adding a history of hypertension and diabetes more than doubled the proportion of participants indicating they would initiate antihypertensive medication, while an additional history of heart failure increased the proportion almost six-fold to $27.8 \%$. In comparison, when presented with a patient with dyslipidemia and a BP of $200 / 110 \mathrm{~mm}$ $\mathrm{Hg}, 61.0 \%$ of participants indicated they would offer an antihypertensive prescription. Adding a history of hypertension, diabetes, and heart failure resulted in $70.5 \%$ reporting that they would offer a new antihypertensive prescription. Results for increasing the dose of a pre-existing antihypertensive were similar (Table 2).

\section{Adjusted predictors of antihypertensive prescription provision}

In the model of offering a new antihypertensive prescription, patient-level characteristics were found to be independently associated with a new prescription: a BP of $200 / 110 \mathrm{~mm} \mathrm{Hg}$ was associated with markedly increased odds (OR 12.9; $p<0.001$ ), compared to $160 / 100 \mathrm{~mm} \mathrm{Hg}$ (Figure 2). A patient with three comorbidities also had substantially increased odds (OR 2.98; $p<0.001$ ), relative to the patient with one comorbidity. Emergency physician factors were not found to be associated with antihypertensive prescription provision. Similarly, in the model of increasing a pre-existing prescription, two patient characteristics (higher BP level [OR 15.2; $p<0.001]$ and three comorbidities [OR 2.3; $p<0.001]$ ) were found to be independently associated with the outcome of interest, while emergency physician characteristics were not.

\section{Follow-up recommendations}

Follow-up recommendations were found to vary by BP value, and to a lesser extent, by patient comorbidity. At 160/100 mm Hg, participants recommended follow-up within a mean of 7, 6, and 5.5 days of ED discharge for a patient with a history of dyslipidemia, hypertension and diabetes, and the further addition of heart failure, respectively. The follow-up recommendation interval was shorter in the scenario with BP 200/110 mm Hg (Table 2).

Table 2. The effect of degree of blood pressure level and patient co-morbidities on emergency department antihypertensive prescriptions.

\begin{tabular}{|c|c|c|c|c|c|c|}
\hline \multirow[b]{2}{*}{$\mathrm{ED} \mathrm{BP}(\mathrm{mm} \mathrm{Hg})$} & \multicolumn{2}{|c|}{$\begin{array}{l}\text { 69-year-old male with history of } \\
\text { dyslipidemia }\end{array}$} & \multicolumn{2}{|c|}{$\begin{array}{l}\text { 69-year-old male with history of } \\
\text { HTN \& diabetes }\end{array}$} & \multicolumn{2}{|c|}{$\begin{array}{l}\text { 69-year-old male with history of } \\
\text { HTN, diabetes \& CHF }\end{array}$} \\
\hline & $160 / 100$ & $200 / 110$ & $160 / 100$ & $200 / 110$ & $160 / 100$ & $200 / 110$ \\
\hline $\begin{array}{l}\text { Start a new antihypertensive } \\
\%(95 \% \mathrm{Cl})\end{array}$ & $5.1(1.4-12.8)$ & $61.0(49.2-72.0)$ & $11.5(5.4-20.8)$ & $65.4(63.8-75.8)$ & $27.8(18.3-39.1)$ & $70.5(59.1-80.3)$ \\
\hline $\begin{array}{l}\text { Increase dose of a pre-existing } \\
\text { antihypertensive } \\
\%(95 \% \mathrm{Cl})\end{array}$ & $5.1(1.4-12.8)$ & $59.7(47.9-70.8)$ & $13.0(6.4-22.6)$ & $63.3(51.7-73.9)$ & $20.8(12.4-31.5)$ & $66.2(54.6-76.6)$ \\
\hline \multicolumn{7}{|c|}{ Recommended days to follow-up with primary care provider: } \\
\hline Mean (SD) & $7.0(5.6)$ & 4.7 (3.3) & $6.3(4.3)$ & $4.5(3.2)$ & $5.5(3.4)$ & $4.0(2.6)$ \\
\hline Median (IOR) & $7.0(5.0-7.0)$ & $3.0(2.0-7.0)$ & $7.0(3.0-7.0)$ & $3.0(2.0-7.0)$ & $7.0(2.0-7.0)$ & $3.0(2.0-7.0)$ \\
\hline
\end{tabular}




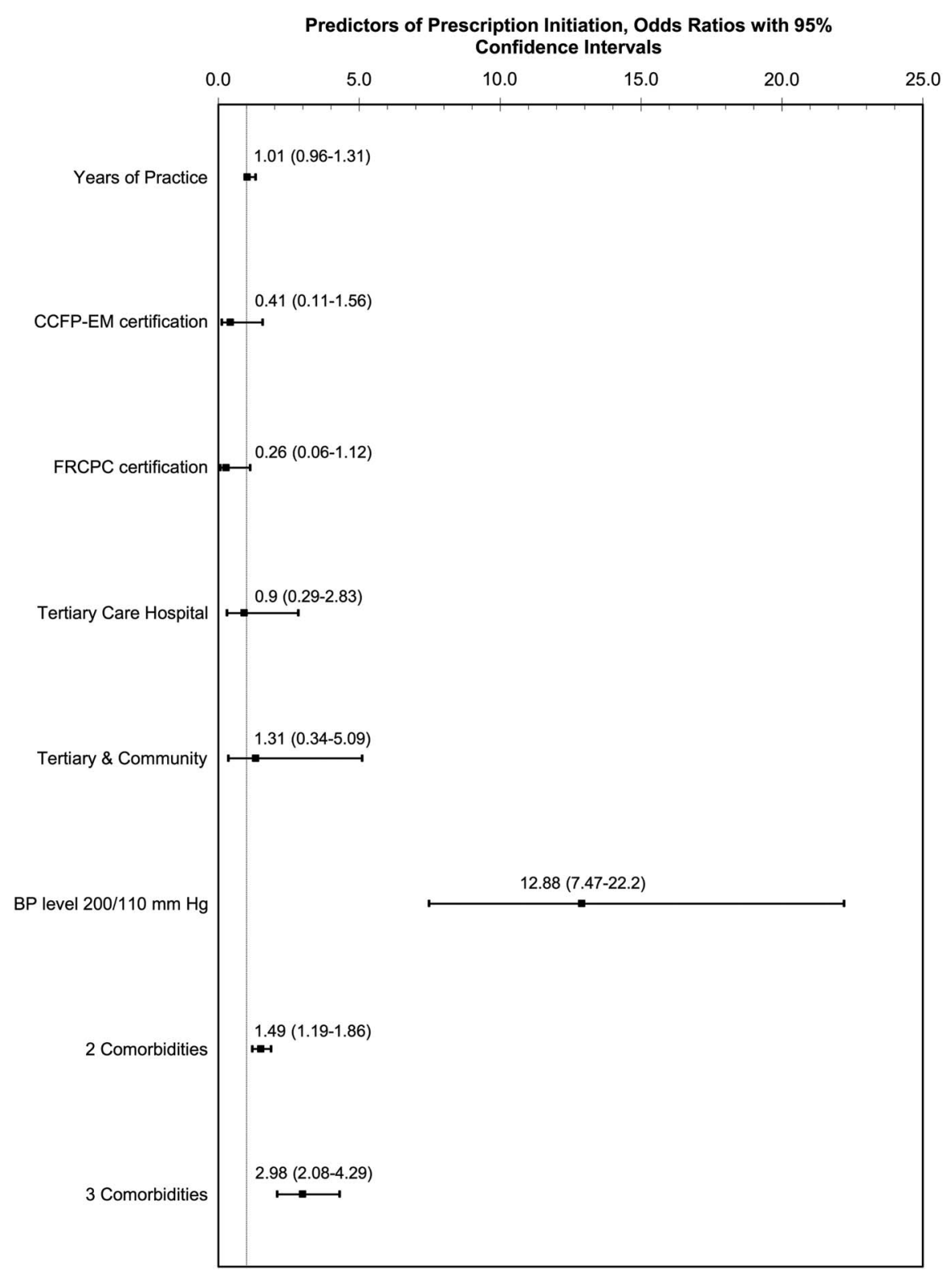

Figure 2. Logistic regression modeling of initiation of a new antihypertensive prescription, using GEEs to account for clustering on physician.

\section{Post-hoc analysis}

Among the participants at the two study sites where chart review was undertaken, $11 \%$ and $71 \%$ reported they would provide a new antihypertensive prescription at $160 / 100$ and $200 / 110 \mathrm{~mm} \mathrm{Hg}$, respectively, for a patient with hypertension and diabetes (two comorbidities). In comparison, the median triage $\mathrm{BP}$ of patients seen at these sites from chart review was $183 / 99 \mathrm{~mm} \mathrm{Hg}$ (IQR 165-198/86-110), and 57.9\% (95\% CI, 53.3-62.5) were provided with a new antihypertensive prescription or increased dose. Among patients with only two comorbidities (data on heart failure was not available), the median triage $\mathrm{BP}$ was 187/91 $\mathrm{mm} \mathrm{Hg}$ and $63.0 \%$ (95\% CI, 54.9-74.0) had documentation of an antihypertensive prescription being provided. Follow-up instructions were documented on the chart in $89.6 \%$ (95\% CI, 86.4-92.2) of charts.

\section{DISCUSSION}

In this study of community and academic emergency physicians attending rounds, only half reported having a "threshold" BP level that would prompt them to 
provide a prescription for a new antihypertensive medication or increase the dose of a pre-existing antihypertensive medication, in patients being sent home with a primary ED diagnosis of hypertension. This likely reflects the lack of evidence in the ED setting on which to base management decisions, ${ }^{10}$ and underscores the lack of consistency that currently characterizes the care of these patients in the ED.

When presented with a specific case, however, the majority of participants reported a willingness to initiate an antihypertensive: for a patient with a BP of 200/110 mm Hg and three cardiac comorbidities, 71\% reported that they would offer an antihypertensive prescription. This might be viewed as a disparity in responses, which could be secondary to a lack of understanding of the initial, more hypothetical, question, or it may arise from the fact that the approach changes depending on the clinical situation (which included an older patient with three comorbidities). While most emergency physicians indicated that they would initiate an antihypertensive medication in certain hypertensive patients, almost a third indicated they would not, even at a very high BP level and in the context of multiple patient comorbidities.

Which approach is better for the patient is unknown, as long-term outcomes after an ED visit for hypertension have received very limited study. The JNC 7 (7th report of the Joint National Committee) recommends against the routine initiation of medications in the $\mathrm{ED},{ }^{3}$ although similar recommendations were absent from JNC 8. ${ }^{16}$ The current ACEP (American College of Emergency Physicians) guidelines are concordant with the JNC 7, with the caveat that they deemed treatment could be warranted in certain patient populations, such as those with poor follow-up care. ${ }^{8}$ A 1967 study found that among 143 discharged men with a diastolic BP between 115 and $130 \mathrm{~mm} \mathrm{Hg}$, those who were not given an antihypertensive prescription had an adverse event rate $6 \%$ higher at 4 months and $36 \%$ higher at 20 months, compared to those who were provided a prescription. ${ }^{17}$ However, the confidence intervals of this finding were wide and the data are not current. A more recent 1999 study of 74 discharged ED patients at a teaching hospital who presented with a systolic or diastolic BP of at least 220 or $110 \mathrm{~mm} \mathrm{Hg}$, respectively, found that $13.5 \%$ of participants returned to the ED within three months with significant cardiovascular complications. ${ }^{18}$ Several studies have assessed shortterm outcomes ${ }^{19,20}$ and found very low frequencies of poor outcomes; however, hypertension is a disease that has significant long-term, rather than short-term, impact. ${ }^{3}$ Large studies on the long-term outcomes are needed in order to guide these management decisions and, in turn, provide consistency of care to such patients across physicians.

While $70 \%$ of emergency physicians in our study reported that they would offer an antihypertensive prescription at a certain $\mathrm{BP}$ and comorbidity level, a retrospective study at a teaching site found that, of those patients recognized to have incidental asymptomatic elevated BP, only $2.4 \%$ were discharged home with an antihypertensive prescription. ${ }^{21}$ However, that study included all-comers to the ED and did not assess average BP values or patient comorbidities. Another study that screened all ED patients for hypertension reported that $8.5 \%$ of patients were offered an antihypertensive prescription if their BP was 160 systolic or 100 diastolic $\mathrm{mm} \mathrm{Hg},{ }^{22}$ a finding similar to our study where $5 \%$ of participants offered an antihypertensive prescription at $160 / 100 \mathrm{~mm} \mathrm{Hg}$.

Provider characteristics have been found to be more strongly associated than patient characteristics with the investigation and management of atrial fibrillation, ${ }^{23,24}$ myocardial infarction, ${ }^{25,26}$ and other conditions ${ }^{27}$. In contrast, our findings suggest that patient characteristics, not provider characteristics, drive ED management decisions for discharged hypertensive patients.

The current literature is consistent in advocating for follow-up care with a primary care provider. ${ }^{7,9,10}$ Currently, however, there are few data to guide the number of days within which such patients should be seen; ACEP has identified this as an area in need of future study. ${ }^{8}$ In our study, recommendations for timing of follow-up care varied by patient presentation, but the large majority of participants endorsed follow-up within seven days.

\section{LIMITATIONS}

The survey was conducted within the GTA using a convenience sample; as such, the results may not be generalizable. Lack of funding prevented extension of the in-person survey to more than seven sites, resulting in a relatively small sample size. We avoided electronic surveys because of their generally poor participation rates. $^{12,13}$ Since physicians who attend rounds may represent the most academically motivated physicians, 
our results may not represent a more general emergency physician population. However, it was our goal to capture the practice patterns of such individuals for use as a potential practice "yardstick." The proportion of participants who reported that they had a threshold BP for prescribing antihypertensive medication was lower than the number who would prescribe using the specific clinical scenario; this could be because some physicians did not feel they had a threshold, but when faced with a specific patient, actually did. Anecdotally, many staff indicated that they wished they could have responded "it depends" to some of the questions. We kept the survey short in order to encourage a high response rate, but recognize and acknowledge that this limited the number of response variations we were able to capture.

\section{CONCLUSIONS}

Half of surveyed emergency physicians report having a BP threshold to start an antihypertensive; BP levels and number of patient comorbidities were associated with a modification of the decision, while physician characteristics were not. Most surveyed physicians recommended follow-up care within seven days of ED discharge.

Acknowledgments: This study was an unfunded project. Dr. Atzema is supported by a New Investigator Award from the HSFO, the Practice Plan of the Department of Emergency Services at Sunnybrook Health Sciences, the Department of Medicine, University of Toronto, and the Sunnybrook Research Institute. The Heart and Stroke Foundation of Ontario had no involvement in the design or conduct of the study, data management or analysis, or manuscript preparation, review, or authorization for submission. This study was supported by the Institute for Clinical Evaluative Sciences (ICES), which is funded by an annual grant from the Ontario Ministry of Health and Long-Term Care (MOHLTC). The opinions, results and conclusions reported in this paper are those of the authors and are independent from the funding sources. No endorsement by ICES or the Ontario MOHLTC is intended or should be inferred.

Competing Interests: Dr. Atzema is supported by a New Investigator Award from the Heart and Stroke Foundation. The authors report no other competing interests.

\section{REFERENCES}

1. World Health Organization. Global Health Risks: Mortality and Burden of Disease Attributable to Selected Major Risks. 1st ed. Geneva: WHO Publications; 2009.
2. Robitaille C, Dai S, Waters C, et al. Diagnosed hypertension in Canada: incidence, prevalence and associated mortality. CMA7 2012;184(1):e49-56.

3. Chobanian AV, Bakris GL, Black HR, et al. The Seventh Report of the Joint National Committee on Prevention, Detection, Evaluation, and Treatment of High Blood Pressure: the JNC 7 report. FAMA 2003;289(19):2560-72.

4. Levy PD, Cline D. Asymptomatic hypertension in the emergency department: a matter of critical public health importance. Acad Emerg Med 2009;16(11):1251-7.

5. Nawar EW, Niska RW, Xu J. National Hospital Ambulatory Medical Care Survey: 2005 emergency department summary. Adv Data 2007;386:1-32.

6. Fields LEL, Burt VLV, Cutler JAJ, et al. The burden of adult hypertension in the United States 1999 to 2000: a rising tide. Hypertension 2004;44:398-404.

7. Mancia G, Fagard RH, Narkiewicz K, et al. 2013 ESH/ESC Guidelines for the Management of Arterial Hypertension: the Task Force for the management of arterial hypertension of the European Society of Hypertension (ESH) and of the European Society of Cardiology (ESC). Blood Press 2013; 22(4):193-278.

8. Wolf SJ, Lo B, Shih RD, et al. Clinical policy: critical issues in the evaluation and management of adult patients in the emergency department with asymptomatic elevated blood pressure. Ann Emerg Med 2013;62(1):59-68.

9. Hackam DG, Quinn RR, Ravani P, et al. The 2013 Canadian Hypertension Education Program recommendations for blood pressure measurement, diagnosis, assessment of risk, prevention, and treatment of hypertension. Can 7 Cardiol 2013;29(5):528-42.

10. Decker WW, Godwin SA, Hess EP, et al. Clinical policy: critical issues in the evaluation and management of adult patients with asymptomatic hypertension in the emergency department. Ann Emerg Med 2006;47(3):237-49.

11. Statistics Canada. Immigration and Ethnocultural Diversity. Available at: http://www12.statcan.gc.ca/nhs-enm/2011/as-sa/ 99-010-x/99-010-x2011001-eng.pdf (accessed March 11, 2014).

12. Hollowell CM, Patel RV, Bales GT, et al. Internet and postal survey of endourologic practice patterns among American urologists. 7 Urol 2000;163(6):1779-82.

13. VanDenKerkhof EG, Parlow JL, Goldstein DH, et al. In Canada, anesthesiologists are less likely to respond to an electronic, compared to a paper questionnaire. Can $\mathcal{F}$ Anaesth 2004;51(5):449-54.

14. Health Quality Ontario. Quality Monitor - Health Quality Ontario. 2011. Available at: http://www.hqontario.ca/portals/0/ Documents/pr/qmonitor-full-report-2011-en.pdf (accessed March 20, 2014).

15. Gilbert EH, Lowenstein SR, Koziol-McLain J, et al. Chart reviews in emergency medicine research: Where are the methods? Ann Emerg Med 1996;27(3):305-8.

16. James PA, Oparil S, Carter BL, et al. 2014 Evidence-based guideline for the management of high blood pressure in adults: report from the panel members appointed to the Eighth Joint National Committee (JNC 8). JAMA 2013; 311(5):507-20.

17. VA Cooperative Study Group on Antihypertensive Agents. Effects of treatment on morbidity in hypertension: Results 
in patients with diastolic blood pressures averaging 115 through $129 \mathrm{~mm} \mathrm{Hg.} 7 A M A$ 1967;202(11):1028-34.

18. Preston RA, Baltodano NM, Cienki J, et al. Clinical presentation and management of patients with uncontrolled, severe hypertension: results from a public teaching hospital. 7 Hum Hypertens 1999;13(4):249-55.

19. Grassi DD, O'Flaherty MM, Pellizzari MM, et al. Hypertensive urgencies in the emergency department: evaluating blood pressure response to rest and to antihypertensive drugs with different profiles. 7 Clin Hypertens (Greenwich) 2008;10(9):662-7.

20. Frei S, Burmeister D, Coil J. Frequency of serious outcomes in patients with hypertension as a chief complaint in the emergency department. FAOA 2013;113(9):664-8.

21. Tilman K, DeLashaw M, Lowe S, et al. Recognizing asymptomatic elevated blood pressure in ED patients: how good (bad) are we? Am 7 Emerg Med 2007;25(3):313-7.

22. Baumann BM, Cline DM, Cienki JJ, et al. Provider selfreport and practice: reassessment and referral of emergency department patients with elevated blood pressure. Am 7 Hypertens 2009;22(6):604-10.

23. Rosen MP, Davis RB, Lesky LG. Utilization of outpatient diagnostic imaging. 7 Gen Intern Med 1997;12(7): 407-11.

24. Stiell IG, Clement CM, Brison RJ, et al. Variation in management of recent-onset atrial fibrillation and flutter among academic hospital emergency departments. Ann Emerg Med 2011;57(1):13-21.

25. Tu JV, Austin PC, Chan BT. Relationship between annual volume of patients treated by admitting physician and mortality after acute myocardial infarction. $7 A M A$ 2001; 285(24):3116-22.

26. Rathore SS, Chen J, Wang Y, et al. Sex differences in cardiac catheterization: the role of physician gender. $7 A M A$ 2001;286(22):2849-56.

27. Berthold HK, Gouni-Berthold I, Bestehorn KP, et al. Physician gender is associated with the quality of type 2 diabetes care. 7 Int Med 2008;264(4):340-50. 